\title{
Initial Results of the S3-Humerus Plate
}

\author{
J. Gille, A.P. Schulz ${ }^{*}$, Ch. Queitsch, A. Paech and Ch. Jürgens
}

BG-Trauma Hospital Hamburg, Bergedorfer Str., 10, D-21033 Hamburg, Germany

\begin{abstract}
Fractures of the humeral head account for 5\% of all fractures and incidence increases with age. Depending on fracture form and patients age a wide variety of therapeutical options exist. Stable fractures can be treated conservatively, while the majority of unstable and displaced fractures require surgical treatment. Many different surgical options are available; open reduction and internal fixation are widely preferred. The S3 Proximal Humerus Plate is a contoured plate to match the complex shape of the proximal humerus. It is designed to be positioned distal to the greater tuberosity preventing subacromial impingement.
\end{abstract}

Between august 1 and 30,2007, 5 patients meeting the inclusion criteria (that is primary operative stabilization within 7 days after trauma in a standardized way and minimal follow up period of 3 month) with acute fractures of the proximal humerus were treated with S3 Proximal Humerus Plate. Follow up was performed using the Constant Score. The mean age was 59.0 years. According to the Neer classification fractures were rated as Neer 2,3 and 4. A mean Constant score of 72.3 (57-86) points was obtained.

We did not observe any complications like humeral head necroses, loss of reduction, deep infection or breakage of the plate.

Keywords: S3 proximal humerus plate, proximal humerus fracture, subchondral support pegs, fixed-angle plate fixation.

\section{INTRODUCTION}

Fractures of the humeral head account for $5 \%$ of all fractures and $45 \%$ of all humeral fractures [1]. With increasing age and decreasing bone quality the incidence accelerates. It is a typical injury for elderly people with a moderate increase in the 6th decade and a climax in the 9th decade. In elderly the trauma is often minor; in younger patients the trauma tends to be major with accompanying injuries of the ipsilateral limb. The prognosis depends on patient's age, the fracture type, the concomitant injuries, and biologic factors such as quality of bone stock and the blood supply to the fragments [2].

The clinical appearance of swelling, pressure pain and painful limited function pinpoints to the diagnosis. Radiographies in 2 planes give information about fracture form. In multifragmented fracture forms a CT scan is helpful.

The most popular classification of humeral head fractures was made up by Neer; it is based on the 4-fragmentclassification by Codman. The classification was modified by Habermeyer and Schweiberer (1989). In clinical practice a classification by the $\mathrm{AO}$ is used, dividing fractures in 3 main and 27 sub groups. Although in theory all fracture types are found, the inter-observer reliability of this classification is relatively low [1].

Depending on fracture form and patients age a wide variety of therapeutical options exist. Although the majority of fractures can be treated conservatively, surgical therapy is steadily increasing [3]. The ambition of operative treatment

*Address correspondence to this author at the BG-Trauma Hospital Hamburg, Bergedorfer Str. 10, D-21033 Hamburg, Germany;

E-mail: aps77@web.de is stable fixation of instable fractures to allow early joint motion. Methods of osteosynthesis range from minimalinvasive methods like screws and K-wires to polyaxial locking plates. In biomechanical testing it has been proven that locking the screws increases the stiffness and the fatigue load and improves fatigue behavior of plate osteosynthesis for the proximal humeral region. Therefore locking can possibly contribute to regain early joint function and thus reduce impairment of motion, particularly in difficult cases $[5,6]$. A frequent problem of plate osteosynthesis in this anatomical area is impingement under the acromion in [7]. New implant designs characterized by a positioning distal to the greater tuberosity need to proove their clinincal benefits.

The purpose of the present study was to evaluate the S3 Humeral Plate System (DePuy, Kirkel-Limbach, Germany); data collection was prospective and 5 consecutive cases were evaluated. All patients were seen 3 month postoperatively. We used the Constant Score as it is widely used to asses shoulder function after trauma [8].

\section{S3- PROXIMAL HUMERUS PLATE}

The S3 Proximal Humeral Plate is a new array of products designed developed with the intention to improve operative treatment of proximal humeral fractures. Contoured plates match the complex shape of the proximal humerus enabling to act as a reduction template to restore the natural anatomy. The S3 plates are designed to be positioned approximately $3.0 \mathrm{~cm}$ distal to the greater tuberosity, thereby theoretically preventing subacromial impingement. The anatomically contoured undersurface aids in restoring proper humeral head rotation. Plate options include a 3, 4, 6, 8 and 11 hole version and an overall length from $70 \mathrm{~mm}$ to 110 $\mathrm{mm}$. The plate's head is constructed with 6 holes; multiple $4.0 \mathrm{~mm}$ subchondral support pegs and screws maintain frac- 
ture reduction (Fig. 1). F.A.S.T (Fixed Angle Screw Targeting) Guide Technology offers preloaded single use disposable drill guides (Fig. 2). Blunt-tipped subchondral support pegs provide improved stability while preventing protrusion through the articular surface.

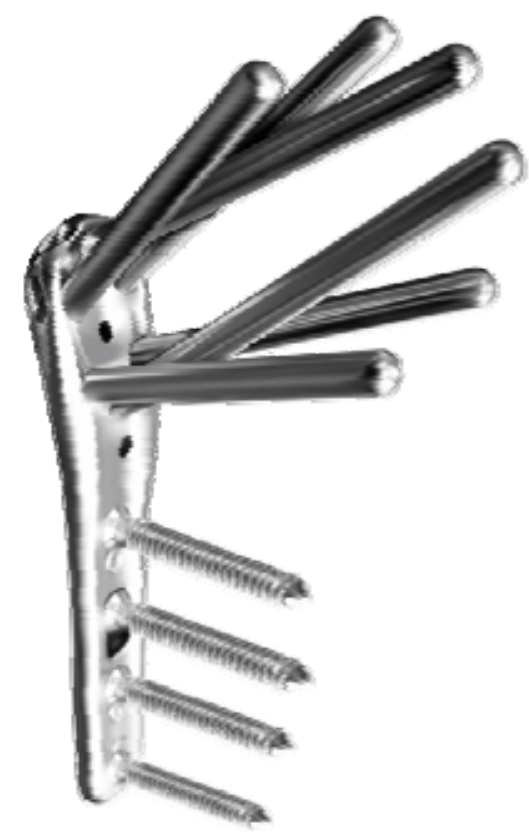

Fig. (1). The S3 Humeral Plate can be used with subchondral support pegs or with screws.
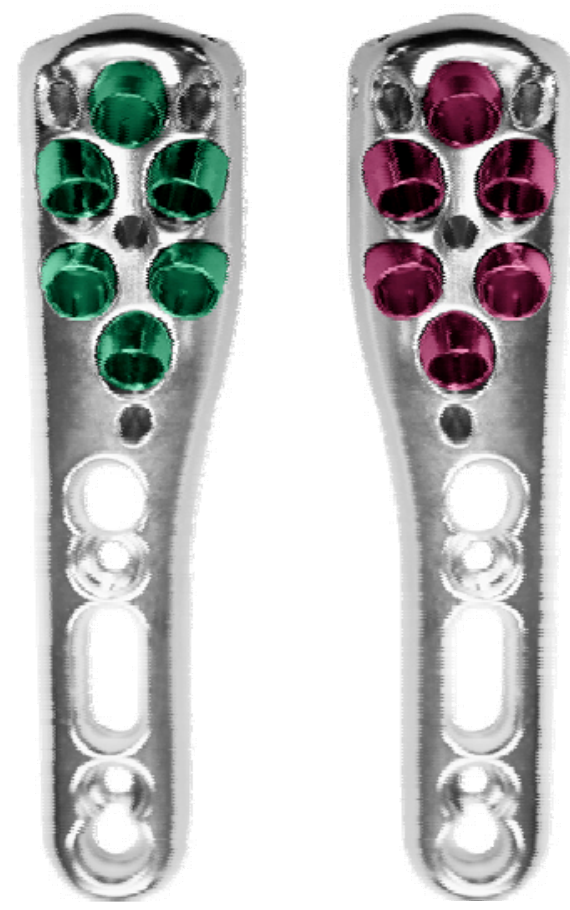

Fig. (2). The S3 Humeral Plate is anatomically contoured to match the complex shape of the proximal humerus.To simplify soft tissue fixation uniquely designed suture holes accomodate multiple passes e.g. to allow tuberosity repair.

To simplify soft tissue fixation uniquely designed suture holes accommodate multiple passes e.g. to allow tuberosity repair (Fig. 3).



Fig. (3). A delta-split approach was used to identify the axillary nerve.

\section{SURGICAL TECHNIQUE OVERVIEW}

Operative treatment was performed in beach-chair position. A deltopectoral approach is commonly used [4]. We used a delta-split approach in this study with identification of the axillary nerve (Fig. 4).

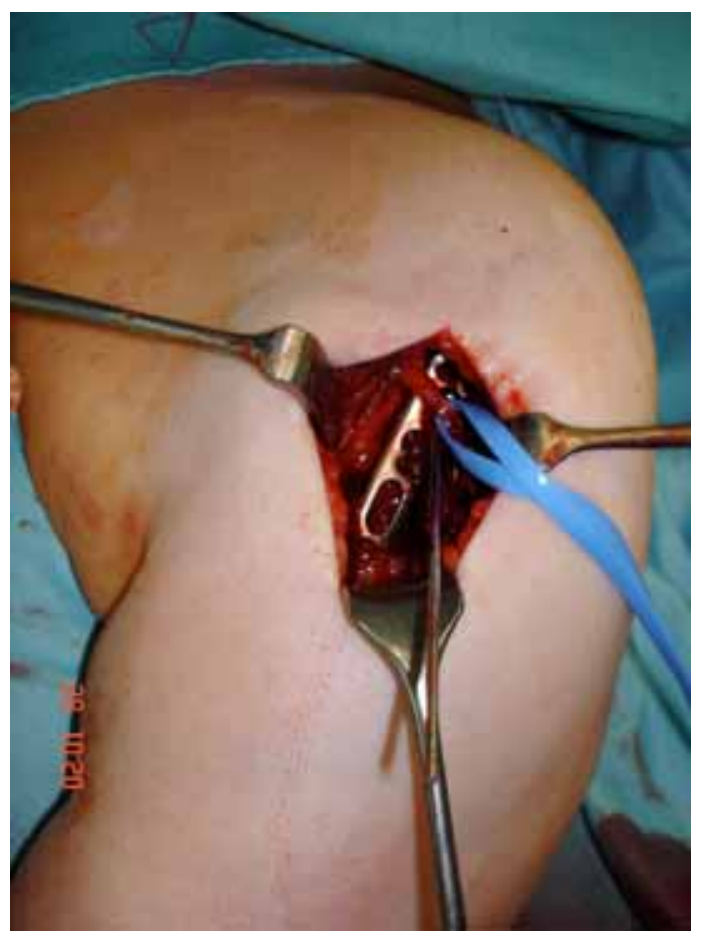

Fig. (4). The plate is positioned distal to the greater tuberosity underneath the axillary nerve. 
After debridement the fracture needs to be reduced through traction and manipulation. The plate is positioned approximately $3.0 \mathrm{~cm}$ distal to the greater tuberosity and just lateral to the bicipital groove under protection of the axillary nerve [4]. The plate is secured to the humeral shaft using a $3.8 \mathrm{~mm}$ multidirectional cortical screw through the oblong hole of the plate. While maintaining the reduction a $2.0 \mathrm{~mm}$ guide wire is placed through the central hole at the head of the plate. The guide wire should be advanced slowly under fluoroscopic imaging until it reaches $2-3 \mathrm{~mm}$ below the subchondral bone (Fig. 5). Using the short $4.0 \mathrm{~mm}$ drill bit, drilling under power through the F.A.S.T Guides across the near cortex until the mechanical safety stop of the drill is performed. The appropriate $4.0 \mathrm{~mm}$ long drill bit is advanced manually through the F.A.S.T Guides under fluoroscopic imaging about 2-3 mm below the subchondral bone. Proximal plate pegs should be torque that they are fully seated. The head of a properly seated peg should sit beneath the surface of the plate. By using the end of the drill guide labeled " $90^{\circ} "$ the remaining shaft screws are drilled. Each $90^{\circ}$ locking shaft screw is fixed with a locking set screw. The tuberosities can be fixed using the side loading suture attachments points; we use Orthocord or PDS for this. The humerus is evaluated under fluoroscopy to assess the final reduction and to confirm proper peg positioning.



Fig. (5). A guide wire is advanced under fluoroscopic imaging.

\section{POSTOPERATIVE MANAGEMENT}

Immediately after surgery AP and axillary films should be taken. The Gilchrist bandage is removed for passive and active-assisted exercises in a pain-free range depending on the biomechanical and biologic circumstances [3].

Plate removal is generally not necessary.

\section{RESULTS}

The fracture reduction and implantation of the S3 humeral plate was possible in all cases. In no case it was necessary to intraoperatively choose another method of osteosynthesis or switch to shoulder prosthesis. There was no significant intra- or postoperative complications in the study population. Especially there are no wound infections or axillary nerve to report of. At the follow up examination a radiograph of the shoulder (a.p. and lateral) showed no sign of humeral head necrosis or loss of reduction.
There was no clinical sign of shoulder impingement at the time of follow up with a satisfactory range of motion (ROM) in all patients. The mean Constant score was determined with $72.3(57-86)$ points.

\section{CASE REPORTS}

Case 1: 68 y.o. female with a blunt trauma to the left shoulder 5 days ago. Radiographs show a humeral head fracture (Neer 3, B2 Habemeyer) with increasing dislocation of the greater tuberosity. Operative treatment was performed using a delta split approach (Fig. 3) and a 4-hole S3 plate. Postoperative films showed anatomical reduction (Fig. 6a,b). At follow up at 12 weeks the R.O.M. was unrestricted without sign of impingement (Fig. 7). At the time of follow up the Constant Score was 86. (a)

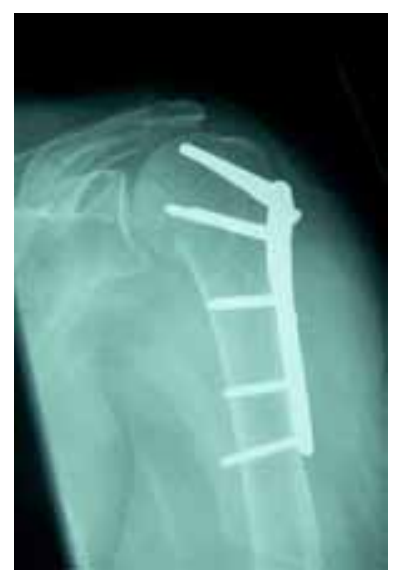

(b)

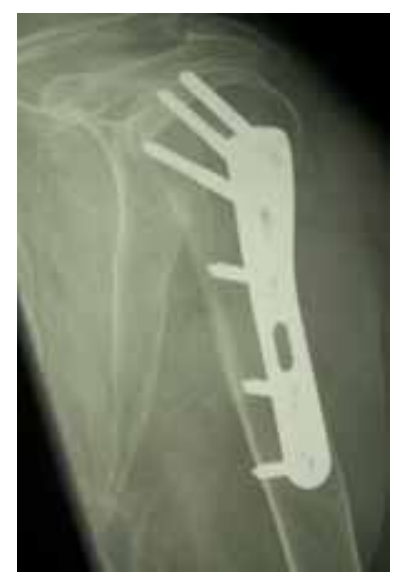

Fig. (6). The humerus is evaluated under fluoroscopy to asses final reduction and confirm proper plate positioning.

Case 2: 57 y.o. male with a downfall from a ladder; radiographs showing a humeral head fracture (Neer 4, B3 Habermeyer). After fracture reduction using a delta split approach a 6 hole version of the S3 Plate was implanted. At the time of follow up the Constant Score were 57.

Case 3: 52 y.o. male; traffic accident while riding a motorcycle. Radiographs showing a humeral head fracture (Neer 2, Habermeyer B2). A delta split approach was performed and a 4-hole S3 plate used. At the time of follow up the Constant Score were 74

\section{DISCUSSION AND CONCLUSION}

The S3 Proximal Humeral Plate can be successfully used in operative treatment of humeral head fractures. It is too early to judge if it performs superior to other angular stable implants. In former studies subacromial impingement of the plate leading to a restricted R.O.M has been reported [2]. The S3 plates are designed to be positioned approximately $3.0 \mathrm{~cm}$ distal to the greater tuberosity, thereby theoretically preventing subacromial impingement. The anatomically contoured undersurface aids in restoring proper humeral head rotation. We did not observe any signs of subacromial impingement using the S3 plate that can be argued by the 


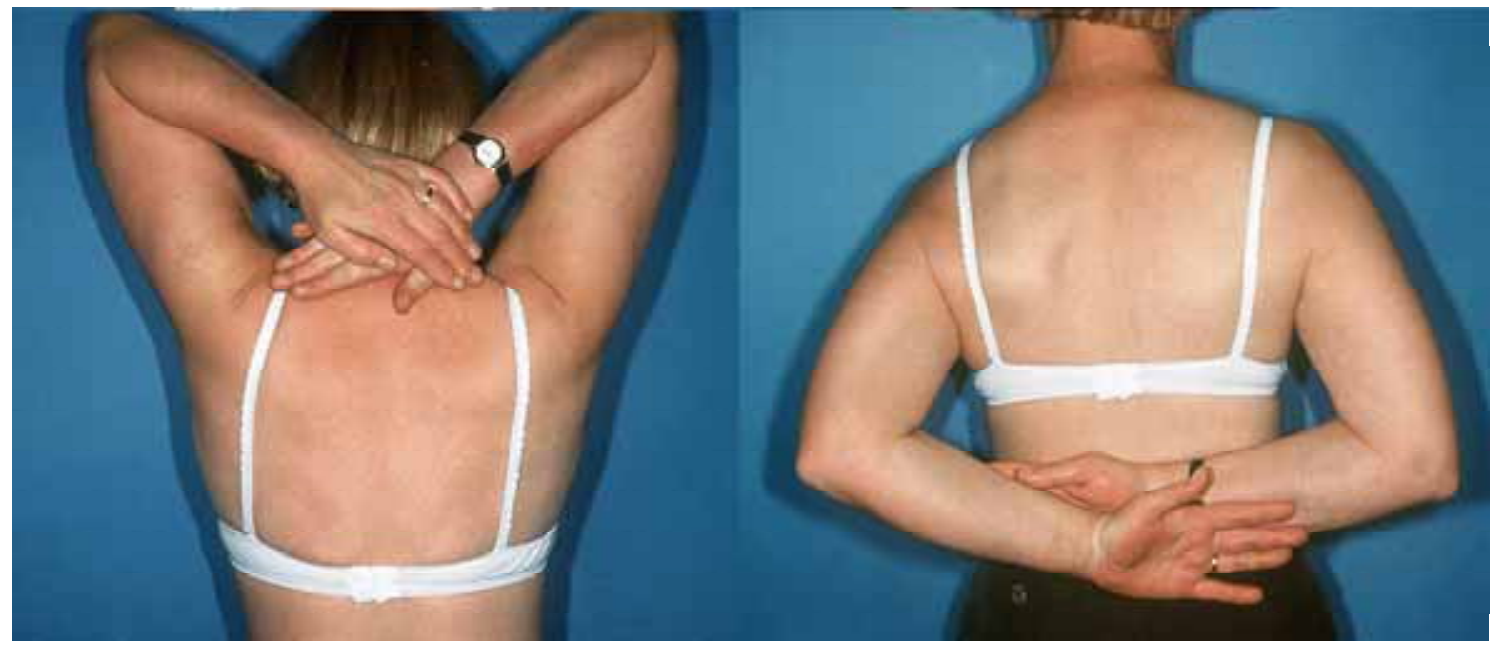

Fig. (7). At follow up at 12 weeks the R.O.M. was unrestricted without sign of impingement.

plate's position distal to the greater tuberosity. At least the theoretical advantage of the positioning of this plate device appears to perform well. A long term follow up with a larger case series is required to judge about this fact.

Locking screws tend to protrude in the articular surface while fracture fragments subsidence leading to a painful limitation of motion [2]. In the reported cases, the blunttipped subchondral support pegs prevented protrusion through the articular surface. We will soon commence a randomized controlled trial to find out if this plate-peg device can reduce the cut out rate.

Based on the data we can present at the moment, it is not possible to state that this device is superior to other locked proximal humeral plates but we could show that it is easy to use and shows comparable short term results.

\section{REFERENCES}

[1] Roderer G, Gebhard F, Erhardt J, Abouelsoud M, Kinzl L. The Non-Contact Bridging Plate: A new fixed-angle device for the minimally-invasive treatment of fractures of the proximal humerus - technique and preliminary results. Unfallchirurg 2007; 110: 50512.

[2] Plecko M, Kraus A. Die winkelstabile Plattenosteosynthese bei Frakturen am proximalen Humerus mit der LPHP (Locking proximal humerus plate). Operat Orthop Traumatol 2005; 17: 25-50.

[3] Voigt C, Lill H. Versorgung proximaler Humerusfrakturen. Trauma Berufskrankh 2007; 9: 43-47.

[4] Suckel A. Minimalinvasive-winkelstabile Plattenosteosynthese bei komplexer Humerusfraktur. Unfallchirurg 2007; 110: 707-10.

[5] Lill H, Hepp P, Korner J. Proximal humeral fractures; how stiff should an implantat be? A comparative mechanical study with new implants in human specimens. Arch Orthop Trauma Surg 2003; 123: 74-81.

[6] Weigel B. Humeruskopffrakturen. In Weigel, Nerlich (Hrsg) Praxisbuch Unfallchirurgie. Springer Berlin, 2005.

[7] Seide K, Treibe J, Faschingbauer M, Schulz AP, Puschel K. Biology and biomechanics in osteosynthesis of proximal humerus. Clin Biomech 2007: 22; 176-82.

[8] Tingart M, Bäthis H, Lefering R. Constant Score and Neer Score. Unfallchirurg 2001: 104; 1048-54.

(C) Gille et al.; Licensee Bentham Open.

This is an open access article licensed under the terms of the Creative Commons Attribution Non-Commercial License (http://creativecommons.org/licenses/bync/3.0/) which permits unrestricted, non-commercial use, distribution and reproduction in any medium, provided the work is properly cited. 